\title{
EVOLUÇÃO, ACESSO E EFETIVIDADE DAS POLIITICAS PÚBLICAS PARA A AGRICULTURA FAMILIAR NO GOVERNO LULA: UM ESTUDO DO CONSELHO MUNICIPAL DE DESENVOLVIMENTO RURAL SUSTENTÁVEL DE VIÇOSA, MINAS GERAIS
}

\author{
Cristina Caetano de Aguiar ${ }^{1}$ \\ Bruno Costa Fonseca ${ }^{2}$
}

\section{Resumo}

Este artigo tem por intento fazer uma análise das políticas públicas voltadas para a agricultura familiar a partir da entrada do Governo Lula no poder, tomando como objeto de estudo o Conselho Municipal de Desenvolvimento Rural Sustentável de Viçosa - MG. Entende-se que este constitui um importante instrumento de articulação entre os agricultores familiares e o Estado. Como metodologia utilizou-se de pesquisa bibliográfica, pesquisa documental, depoimento de técnicos e conversas com pesquisadores ligados diretamente ao Conselho de Viçosa. Desse modo, foi realizada, através do método análise de conteúdo, uma discussão acerca das abordagens das políticas públicas debatidas no Conselho estudado, de modo que se objetivou analisar a relação entre a participação, a contribuição e o entendimento dos agricultores familiares no que tange à efetividade

\footnotetext{
${ }^{1}$ Bacharela em Cooperativismo pela Universidade Federal de Viçosa (UFV). Mestranda em Administração com ênfase em Administração Pública pela UFV. Possui experiência na área de organizações coletivas com ênfase em Cooperativismo e Associativismo e Organização do Quadro Social - OQS . Foi bolsista de Iniciação Científica PIBIC/CNPq e consultora de projetos na ONG NACAB. Email: cristina.aguiar@ufv.br

${ }^{2}$ Mestrando em Extensão Rural pela Universidade Federal de Viçosa, possui graduação em Bacharel em Cooperativismo pela mesma instituição. Atualmente é consultor de projetos na Ong Nacab e pesquisador no Grupo de Estudos Rurais: Agriculturas e Ruralidades (GERAR). Possui experiência na área de organizações coletivas com ênfase em Economia Solidária, Cooperativismo e Associativismo. Email: bruno_fonsecacosta@hotmail.com
} 
EVOLUÇÃO, ACESSO E EFETIVIDADE DAS POLÍTICAS PÚBLICAS PARA A AGRICULTURA FAMILIAR NO GOVERNO LULA: UM ESTUDO DO CONSELHO MUNICIPAL DE DESENVOLVIMENTO RURAL SUSTENTÁVEL DE VIÇOSA, MINAS

das políticas públicas atinentes ao meio rural. Assim, conclui-se que o Conselho é responsável por aproximar os agricultores das políticas públicas, no entanto, esse processo ocorre de modo tecnicista. Não obstante, este instrumento não chega a todos os agricultores, além de que a participação desses atores não ocorre de forma efetiva, o que demonstra certa fragilidade e deficiência desse tipo de organização.

Palavras-chave: Agricultura familiar, políticas públicas, Conselho Municipal de Desenvolvimento Rural Sustentável.

\title{
EVOLUTION, ACCESS AND EFFECTIVENESS OF PUBLIC POLICY FOR THE FAMILY AGRICULTURE IN LULA GOVERNMENT: A STUDY OF THE CITY COUNCIL OF RURAL DEVELOPMENT OF SUSTAINABLE VIÇOSA - MINAS GERAIS, STATE, BRAZIL
}

\begin{abstract}
This article is meant to make an analysis of public policies for family agriculture from the entrance of the Lula government in power, taking as its object of study the Municipal Council for Sustainable Rural Development of Viçosa - Minas Gerais, State, Brazil. It is understood that this is an important instrument of coordination between the farmers and the state. The methodology used is a bibliographic research, documentary research, technical testimony and conversations with many researchers linked directly to the Board of Viçosa. Thus was performed through the content analysis method, a discussion of the approaches of public policies discussed in the study, so that it aimed to focus on the relationship between participation, contribution and understanding of family agriculture in respect to effectiveness of public policies relating the rural environment. Like this, it is concluded that the Council is responsible for bringing the farmers of public policy, however, this process occurs technicist mode. Nevertheless, this instrument does not reach all
\end{abstract}


farmers, and that participation of these actors does not occur effectively, showing a certain weakness and deficiency of this organization type.

Key-words: Family agriculture, public policy, the City Council for Sustainable Rural Development.

\section{INTRODUÇÃO}

Desde que o ser humano começou a dominar a natureza com as técnicas de agricultura as sociedades começaram a surgir e passaram a crescer, assim como a população, com a atinente necessidade de alimentação, culminando, por assim ser, em processos de inovação da agricultura. Assim, por mais que hoje exista uma sociedade predominantemente urbana, é impossível entender sua origem sem o auxílio do rural e dos processos de evolução da agricultura.

Com a consolidação do capitalismo e a Revolução Industrial nos séculos XVIII e XIX houve um elevado crescimento da produção de alimentos, conduzindo a um grande aumento demográfico. Não obstante, as correntes de pensamento Malthusianas ${ }^{3}$ propunham que a população crescia geometricamente, enquanto que a produção de alimentos aritmeticamente, ou seja, essa teoria preconizava que, com o passar dos tempos, uma imensa onda de fome iria afetar o mundo, configurando em um anunciado desastre social.

Destarte, surgiu a Revolução Verde, sustentada pela teoria Malthusiana. No espaço rural, a Revolução Verde foi representada, sobretudo, pela inseminação dos "pacotes tecnológicos", além de créditos agrícolas para a grande produção, utilização de grandes maquinários, com tecnologias que atendiam os grandes produtores (MOREIRA, 2000). Esse processo resultou em graves impactos sociais, com a marginalização e exclusão de distintos grupos sociais do campo, que não conseguiram se projetar no novo cenário de uma

\footnotetext{
${ }^{3}$ A corrente Malthusiana é derivada da teoria, de mesmo nome, criada por Tomas Robert Malthus (1766-1834), que era economista e demógrafo inglês.
} 
EVOLUÇÃO, ACESSO E EFETIVIDADE DAS POLÍTICAS PÚBLICAS PARA A AGRICULTURA FAMILIAR NO GOVERNO LULA: UM ESTUDO DO CONSELHO MUNICIPAL DE DESENVOLVIMENTO RURAL SUSTENTÁVEL DE VIÇOSA, MINAS GERAIS

agricultura prioritariamente competitiva, completamente dependente dos novos processos tecnológicos do campo.

A partir de então, começou-se a intensificar o processo dicotômico entre a agricultura patronal e a agricultura familiar. Em termos de incentivos governamentais, fica ainda mais evidente a exclusão de grupos dependentes da agricultura familiar, entendida como atrasada na época. O Neoliberalismo, presente nos debates políticos do Governo Collor (1990), propunha abrir as fronteiras agrícolas para a chamada globalização. No entanto, foi a partir do Governo de Fernando Henrique Cardoso- FHC (1995) que o projeto Neoliberal se consolida, por meio da promessa de incluir o Brasil entre os países do primeiro mundo. Impulsionado pelas ordens do Fundo Monetário Nacional (FMI), o Governo FHC se orientou para a criação de algumas políticas agrícolas para o meio rural brasileiro, por citar: aumento da exportação de comodities ${ }^{4}$, pela abertura do mercado externo; integração seletiva de pequenos agricultores nas agroindustrias; desaparecimento da agricultura familiar de subsistência; estímulo às grandes fazendas; prioridades no que tange ao capital e tecnologia e menos preocupação com terra, dentre outras, que seguiam o modelo norte-americano de agricultura (LOUREIRO, 2003).

Concomitantemente, emergiram grandes pressões dos movimentos sociais no campo para que o Estado se sensibilizasse com as desigualdades sociais no espaço rural. Nesse âmbito, algumas políticas públicas foram criadas em favor da agricultura familiar, da Reforma Agrária e do desenvolvimento local. Contudo, o desenvolvimento preconizado pelo governo prioritariamente, de acordo com Alentejano (2004), era a produção da monocultura em larga escala para exportação, ou seja, baseado no incentivo ao agronegócio.

Assim, eleito por uma massa de trabalhadores e militantes de movimentos sociais, o Governo Lula (2003) se fundamentou em um importante programa de Reforma Agrária, na defesa da

\footnotetext{
${ }^{4}$ Commodities é um termo ligado ao agronegócio, que constitui em compromissos de compra e venda de produtos agrícolas padronizados nas bolsas de mercadorias destes produtos.
} 
agricultura familiar e de luta contra a pobreza no campo (SABOURIN, 2007). Para muitos, essa nova era, consistiu em um avanço das políticas públicas no campo, com a real participação dos agricultores e dos movimentos sociais de base nas propostas de criação e reformulação das mesmas. De que o Governo Lula optou pelas políticas públicas voltadas para a agricultura familiar em contraponto ao agronegócio, não se tem dúvidas. Entretanto, é preciso uma averiguação da real efetividade e acesso a essas políticas, ou seja, analisar até que ponto os agricultores familiares de fato conseguiram/conseguem usufruir de tais políticas.

Desse modo, motivado por esta questão, este trabalho tem por objetivo analisar a evolução das políticas públicas para a agricultura familiar com a entrada do Governo Lula no poder, tendo como objeto de análise o Conselho Municipal de Desenvolvimento Rural Sustentável - Viçosa - MG, pois, a priori, este se constitui como um importante espaço de discussão sobre políticas públicas. De forma análoga, elegeu-se como pergunta norteadora para a proposta desta pesquisa a seguinte: os Conselhos de Desenvolvimento Rural Sustentável constituem, de fato, um espaço de diálogo e participação entre os agricultores familiares e o poder público no âmbito das políticas públicas para o meio rural, corroborando a evolução das mesmas a partir da entrada de Lula no Governo?

\section{AGRICULTURA FAMILIAR}

O termo agricultura familiar não é novo, no entanto, as discussões sobre seu papel e sua importância vêm ganhando força e espaço nos atuais meios acadêmicos, nas políticas de governo e nos movimentos sociais, além de estarem sendo impulsionadas por debates embasados no desenvolvimento rural sustentável, na geração de emprego e na segurança alimentar.

Tomando como base as estatísticas mais atuais, que já se encontram defasadas, existem no Brasil 5.175.489 estabelecimentos rurais, o que representa 329. 941. 393 hectares sendo 4.367 .902 da agricultura familiar e 807.587 hectares não-rurais. Os agricultores familiares representam $85,2 \%$ do total de estabelecimentos rurais, 
EVOLUÇÃO, ACESSO E EFETIVIDADE DAS POLÍTICAS PÚBLICAS PARA A AGRICULTURA FAMILIAR NO GOVERNO LULA: UM ESTUDO DO CONSELHO MUNICIPAL DE DESENVOLVIMENTO RURAL SUSTENTÁVEL DE VIÇOSA, MINAS GERAIS

pois ocupam $30,5 \%$ da área total e são responsáveis por $37,9 \%$ do valor bruto da produção agropecuária nacional (Censo Agropecuário 2006). Esse conjunto de informações mostra que, mesmo detendo menor proporção de terra e de financiamento, os agricultores familiares produzem e empregam mais do que a agricultura patronal. Logo, conclui-se que os agricultores familiares utilizam os recursos produtivos de forma mais eficiente que os patronais.

Existem dificuldades em definir o que seria a agricultura familiar. Segundo Abramovay (2000), a agricultura familiar não pode empregar trabalhadores permanentes, no entanto, pode utilizar de serviços temporários de até cinco pessoas. Guanziroli e Cardim (2000) definem como agricultores familiares todos os agricultores que exercem a direção do trabalho na propriedade juntamente com seus familiares, que não possui mão de obra contratada em número superior ao da mão de obra familiar, e que a área da propriedade não exceda um limite ${ }^{5}$ que é estabelecido para cada região do país. Para Bittencourt e Bianchini (1996), agricultor familiar é aquele que tira da agricultura sua principal fonte de renda, que utiliza como força de trabalho os membros da família. A contratação temporária de terceiros é permitida, porém, a mão de obra familiar deve ser igual ou maior a $75 \%$ do total utilizado no estabelecimento.

Nota-se que a definição de agricultura familiar é baseada no tipo de mão de obra utilizada, no tamanho da propriedade, na direção dos trabalhos e na renda gerada pela atividade agrícola. Contudo, é possível notar um ponto em comum em todas as definições: a família é proprietária dos meios de produção e assume o trabalho no estabelecimento.

Nesse sentido, Gasson e Errington (1993) apontam seis características básicas da agricultura familiar, quais sejam: a gestão é feita pelos proprietários; os responsáveis pelo empreendimento estão ligados entre si por laços de parentesco; o trabalho é fundamentalmente familiar; o capital pertence à família; o patrimônio

\footnotetext{
${ }^{5}$ Este limite é medido em número de módulo fiscal, unidade de medida em ha, que é diferente para cada município. As propriedades, para serem consideradas da agricultura familiar, não podem exceder 4 módulos fiscais.
} 
e os ativos são objetos de transferência intergeracional no interior da família e os membros da família vivem na unidade produtiva.

Por fim, salienta-se que a agricultura familiar é caracterizada pela relação entre terra, trabalho e família, e apresenta uma série de especificidades e diferenciação regional e local. É válido ressaltar que os agricultores não encaram seus negócios como uma empresa, mas procuram suprir as necessidades de seus familiares, logo, nesse processo, família e negócio estão intimamente ligados (CARMO, 2008).

\section{EVOLUÇÃO DAS POLÍTICAS PÚBLICAS NO MEIO RURAL BRASILEIRO}

De forma geral, as políticas públicas surgiram com o desígnio de nortear a ação do poder público - com a criação de regras e procedimentos - para estabelecer as relações entre o Estado e a sociedade civil, proporcionando assim, uma mediação entre esses atores. Logo, as políticas públicas se tornaram um valioso instrumento de viabilização (leis, programas, linhas de financiamentos) de ações que normalmente se utilizam de aplicações de recursos públicos. Em suma, as políticas públicas têm como objetivo atender a demandas, em sua maioria, dos setores colocados à margem da sociedade (TEIXEIRA, 2002).

Não obstante, ao se pensar no histórico de políticas públicas para o meio rural brasileiro, o contexto histórico-social em que se desenvolveu desde o princípio era, sobretudo, o do crescimento econômico como base, acelerando desse modo o processo de industrialização almejado pelo Estado brasileiro. As políticas desse quadro eram concebidas a partir dos interesses econômicos das oligarquias rurais e urbano-industriais, deixando de lado qualquer tipo de discussão e participação dos demais segmentos da sociedade, tais como: pequenos produtores rurais, grupos indígenas, ribeirinhos, quilombolas, entre outros (HESPANHOL, 2008).

Este contexto começou a mudar. Segundo Bulla e Leal (2004), a partir da década de 80 inicia-se o processo de democratização do país, que se constituiu em um marco para as políticas públicas no campo. Com a ruptura do regime militar, em 1979, a sociedade civil organizada deu visibilidade aos setores 
EVOLUÇÃO, ACESSO E EFETIVIDADE DAS POLÍTICAS PÚBLICAS PARA A AGRICULTURA FAMILIAR NO GOVERNO LULA: UM ESTUDO DO CONSELHO MUNICIPAL DE DESENVOLVIMENTO RURAL SUSTENTÁVEL DE VIÇOSA, MINAS GERAIS

excluídos e a luta pelos direitos foi corroborada. Ademais, com a Constituição Federal de 1988 surgiram, no cenário brasileiro, processos de intensificação da participação social, da autogestão, das discussões acerca de um desenvolvimento rural sustentável, e de formas de organização coletiva, culminando em uma nova maneira de se olhar para as questões do meio rural.

Nesse período verificam-se distintas reivindicações por políticas públicas no campo, sobretudo, para agricultura familiar, pois o aumento do êxodo rural e uma constante desvalorização das atividades agrícolas remetiam à necessidade da criação de um programa que levasse em consideração a diversidade do meio rural. Destarte, em 1994 foi criado o Programa de Valorização da Pequena Produção Rural (PROVAP), que se configurava em uma linha de crédito voltada para o meio rural. Entretanto, essa política estava destinada ao malogro, devido às rigorosas exigências impostas ao público alvo (PEDRON e KLEIN, 2004). Posteriormente, houve o surgimento do Programa Nacional de Fortalecimento da Agricultura Familiar (PRONAF), em $1995^{6}$, com o objetivo de fortalecer as atividades produtivas geradoras de renda das unidades familiares de produção, com linhas de financiamento rural adequadas à sua realidade. Segundo Denardi, foi à primeira política pública diferenciada e a favor dos agricultores familiares brasileiros. Ainda para o autor, o PRONAF pode ser considerado uma das maiores conquistas dos movimentos sociais e sindicais de trabalhadores rurais nas últimas década, pois "suas lutas podem ser simbolizadas pelos Gritos da Terra Brasil, liderados pela Contag e, no caso da Região Sul, pelas ações e pressões da Frente Sul da Agricultura Familiar" (DENARDI, 2001, p. 58). Para Gazolla e Schneider (2004), o surgimento do PRONAF é considerado um marco histórico da intervenção do Estado sobre o meio rural brasileiro. Os agricultores familiares, que até então eram desprovidos das políticas públicas para o meio rural, se tornaram privilegiados na ação governamental, demonstrando assim a importância que esta categoria social possui para o desenvolvimento socioeconômico do país.

\footnotetext{
${ }^{6}$ É possível notar desacordos no que se refere ao surgimento desta política pública.
} 
Neste sentido, também em 2003, foi instituído o Programa de Aquisição de Alimentos (PAA), sendo regulamentado inicialmente em agosto de 2006 pelo Decreto no 5.873/06, como parte inerente de uma das ações estruturais do programa Fome Zero. Essa política tem por finalidade adquirir alimentos de agricultores familiares e destiná-los a pessoas em situação de insegurança alimentar ou programas sociais locais. Para Cerqueira, Rocha e Coelho (2006), o programa é de suma importância, pois tenta considerar a magnitude da agricultura familiar no meio rural brasileiro e, especificamente, os principais problemas enfrentados por tal segmento. Para Grisa et al. (2009), a criação do PAA é derivada de dois campos de discussão na década de 1990: o primeiro traz à tona a discussão sobre a segurança alimentar e nutricional, que teve início no final da década de 1980, com maior ênfase nos anos de 1990, e finalmente, ganhando notório espaço no governo Lula a partir de 2003. O segundo está relacionado diretamente com os debates do reconhecimento da importância da agricultura familiar, que sempre ficou à margem das ações de intervenção do Estado. Para os autores, apesar do PAA ainda ser um programa recente, é possível perceber que, cada vez mais tem conseguido legitimidade social nos espaços político-institucionais, junto aos movimentos sociais, organizações não-governamentais, institutos de pesquisa e na academia.

É importante destacar também o Programa Nacional de Alimentação Escolar (PNAE), que iniciou no Brasil em 1995. Conhecido no Governo Lula como merenda escolar, o programa ganhou maior visibilidade a partir de 2009, com a Lei 11.947/ 2009. De acordo com o artigo 14 da referida lei, no mínimo $30 \%$ (trinta por cento) dos recursos financeiros repassados pelo Fundo Nacional de Desenvolvimento da Educação (FNDE) devem ser utilizados na compra de gêneros alimentícios da agricultura familiar e do empreendedor rural, dando prioridade, aos assentamentos da Reforma Agrária, às comunidades tradicionais indígenas e às comunidades quilombolas. Para Santos (2009), este programa, juntamente com o PAA, resulta em um mercado destinado à agricultura familiar de, aproximadamente, $R \$ 1,2$ bilhões/ano, contribuindo significativamente para o desenvolvimento rural no país. 
EVOLUÇÃO, ACESSO E EFETIVIDADE DAS POLÍTICAS PÚBLICAS PARA A AGRICULTURA FAMILIAR NO GOVERNO LULA: UM ESTUDO DO CONSELHO MUNICIPAL DE DESENVOLVIMENTO RURAL SUSTENTÁVEL DE VIÇOSA, MINAS

Por fim, é válido ressaltar que houve uma evolução quanto às políticas públicas no meio rural brasileiro, contudo, o que se tem visto são enormes desafios para sua implementação, fiscalização e sustentação.

\section{PROCEDIMENTOS METODOLÓGICOS}

Entende-se que a proposta deste papper se configura em uma pesquisa descritiva. Segundo Gil, uma pesquisa descritiva propende "[...], como objetivo primordial, à descrição das características de determinada população ou fenômeno ou, então, ao estabelecimento de relações entre variáveis". Ainda para o mesmo autor, "algumas pesquisas descritivas vão além da simples identificação da existência de relações entre variáveis, pretendem determinar a natureza dessa relação" (GIL, 2002, p. 42).

Assim, optou-se por uma pesquisa com características predominantemente qualitativas, embora, como explicita Triviños (1987), uma pesquisa possa ser concomitantemente quantitativa e qualitativa, inviabilizando a dicotomia entre essas modalidades. Contudo, o autor é enfático a se referir aos trabalhos com enfoque qualitativo:

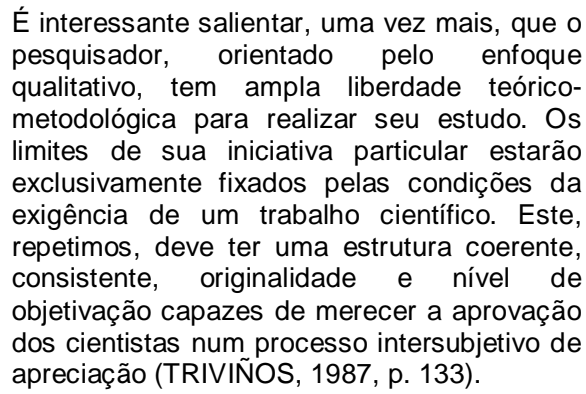

Desse modo, inicialmente foi realizada uma revisão bibliográfica que possibilitasse compreender os conceitos ligados à 
agricultura familiar, bem como entender os processos acerca das políticas públicas para o meio rural no Brasil. Igualmente, teve como alvo, através de consulta bibliográfica, conhecer o Conselho Municipal de Desenvolvimento Rural Sustentável, "campo" de pesquisa para este trabalho.

Empregou-se também a pesquisa documental. Esta é bastante similar à pesquisa bibliográfica, contudo, o elemento diferenciador está na origem das fontes. A pesquisa bibliográfica nos direciona para as diferentes contribuições de autores sobre um mesmo tema, configurando-se assim em uma fonte secundária. Por outro lado, a pesquisa documental recorre a materiais que ainda não receberam nenhum tipo de tratamento analítico, ou seja, fontes primárias (SÁ-SILVA; ALMEIDA e GUINDANI, 2009). Nesse sentido, foram utilizados as atas e o regimento interno do CDRS, além de matérias de jornais com notícias sobre o mesmo. A análise de bancos de dados do governo foi de igual importância.

Outra técnica de coleta de dados utilizada foi a entrevista, onde colheu o depoimento da chefe da Empresa de Assistência Técnica e Extensão Rural, responsável pelas comunidades rurais no entorno de Viçosa - Minas Gerais, além de conversas com os professores e pesquisadores da Universidade Federal de Viçosa que possuem relação direta com o CMDRS, a fim de elucidar algumas questões. Estas conversas possibilitaram traçar as fases do trabalho, assim como orientar os pressupostos teóricos do mesmo.

Por seguinte, os dados coletados foram sujeitos à técnica de análise de conteúdo, com intuito de mapear elementos que dessem suporte ao objetivo deste trabalho. Segundo Oliveira et al. (2003), a análise de conteúdo é uma das técnicas de pesquisa mais antigas desenvolvida sob e ótica das ciências sociais. Esta técnica "[...] oferece um modelo experimental bem definido, que parte de uma concepção orientada ao entendimento do objeto de estudo [...]" (OLIVEIRA et al., 2003, p.17).

Por fim, os resultados finais foram classificados e ordenados de modo a contribuir (ou não) para este trabalho, culminando assim, nos registros aqui apresentados. 
EVOLUÇÃO, ACESSO E EFETIVIDADE DAS POLÍTICAS PÚBLICAS PARA A AGRICULTURA FAMILIAR NO GOVERNO LULA: UM ESTUDO DO CONSELHO MUNICIPAL DE DESENVOLVIMENTO RURAL SUSTENTÁVEL DE VIÇOSA, MINAS GERAIS

\section{OBJETO DE ANÁLISE: CONSELHOS}

Os conselhos são instrumentos antigos de participação popular, assim como a própria democracia participativa. Segundo Gohn (2001), eles tiveram origem nos clãs visigodos e alguns se tornaram famosos tais como, a Comuna de Paris, os Conselhos dos Sovietes Russos, os Conselhos Operários de Turim.

No Brasil, os conselhos tiveram origem na década de 80 , devido às mudanças ocorridas no processo de democratização e de descentralização das políticas públicas, e devido à necessidade de se criar instrumentos que pudessem mediar uma nova relação entre o Estado e a sociedade civil. Após a Constituição Federal de 1988 houve um grande aumento no número de conselhos estaduais e municipais, em diferentes setores, como educação, saúde, infância, meio ambiente e desenvolvimento rural - todos com o escopo de criar canais de participação dos diferentes atores sociais. As estratégias de participação permitem que as comunidades deixem o papel de meros figurantes e assumam o papel de protagonistas de seu próprio bem-estar (SAYAGO, 2007).

Os conselhos podem assumir formas diferenciadas, podendo ser exclusivamente consultivos e sem participação da sociedade civil ou os chamados conselhos gestores de políticas públicas ou setoriais. Apesar dessa diversidade de natureza e finalidade, todos são definidos como espaços intermediários de debate com atuação livre da sociedade civil e base territorial definida, que possuem geralmente funções consultivas ou deliberativas e de controle social, não suprimindo as instâncias formais de governo (AVRIZTER e PEREIRA, 2005). Assim, os conselhos "[...] assumem o papel ora de organismo de luta pelo poder e de organização econômica, ora de mecanismo de gestão, substituindo o aparato administrativo anterior e constituindo novas relações de poder" (GOHN, 2001 apud TEIXEIRA, 2000a, p.101).

Segundo Côrtes, a institucionalização dos conselhos se concretizou devido "[...] à capacidade dos atores sociais transferirem práticas e informações do nível social para o nível administrativo" (2005, p. 19). Desse modo, esses espaçõs permitem ao cidadão comum, que possui, muitas vezes, somente a própria experiência, a 
participação na tomada de decisão sobre políticas públicas (COELHO, 2004).

Comparado às esferas públicas tradicionais, os conselhos se diferem pelo seu caráter inclusivo, pelo aprofundamento dos debates públicos e pela diminuição dos custos de informação, contribuindo assim para a melhoria da qualidade da opinião pública. A participação por meio dos conselhos seria responsável pela articulação entre a burocracia governamental e os usuários e beneficiários das políticas públicas, além de promover a transparência nos debates e visibilidade das ações governamentais. Ademais, os conselhos exercem uma "função pedagógica", contribuindo para a construção da cidadania, do conhecimento governamental e da reconfiguração dos padrões de convivência democrática, ao tempo em que conferindo aos membros um sentimento de pertencimento e identificação recíproca (TATAGIBA, 2002).

O Conselho Municipal de Desenvolvimento Rural Sustentável do Município (CMDRS) de Viçosa/MG é um órgão de caráter consultivo e deliberativo da Política de Desenvolvimento Rural do Município, criado pela Lei Municipal no 1.591/2004. Os seus membros são compostos de forma paritária por representantes do Poder Público, de entidades civis e rurais, e estabelecem as ações desejadas para implantação na zona rural, de modo que estas possam contribuir para 0 aumento da produção agropecuária, geração de emprego/ renda e melhoria da qualidade de vida das famílias rurais. O CMDRS encontra-se em plena atividade, sendo constituído por representantes do Poder Executivo Municipal, Poder Legislativo Municipal, IEF, EMATER, EPAMIG/IMA, UFV, ONGs, Sindicato Rural Patronal, Escolas Rurais, Associação de Moradores de Comunidades Rurais e Associação de Pequenos Produtores.

Por ser um espaço privilegiado de participação da sociedade civil, o CMDRS foi escolhido como objeto de análise deste estudo, a fim de verificar se, de fato, ocorre a participação dos agricultores familiares nas reuniões promovidas pelo conselho, visto que, uma de suas competências é a de "assegurar a participação efetiva dos segmentos promotores e beneficiários das atividades agropecuárias desenvolvidas no município" (CONSELHO DE DESENVOLVIMENTO RURAL SUATENTÁVEL, 2004, p.3). 
EVOLUÇÃO, ACESSO E EFETIVIDADE DAS POLÍTICAS PÚBLICAS PARA A AGRICULTURA FAMILIAR NO GOVERNO LULA: UM ESTUDO DO CONSELHO MUNICIPAL DE DESENVOLVIMENTO RURAL SUSTENTÁVEL DE VIÇOSA, MINAS

\section{RESULTADOS E DISCUSSÕES}

Atualmente, as políticas públicas do Estado para o meio rural preveem uma maior participação e um maior envolvimento das comunidades locais no processo de elaboração e discussão das políticas, tendo como objetivo, rever os antigos modelos de planejamento, gestão e desenvolvimento rural. Um dos mecanismos adotados para mediar essa relação entre Estado e sociedade civil são os Conselhos Gestores de Políticas Públicas.

Assim, no dia nove de setembro de 2004 foi criado o CMDRS em Viçosa. Considera-se que o conselho, por si só - além de objeto de estudo -, é parte inerente da evolução das políticas públicas para - meio rural, pois é possível averiguar que este se torna um importante instrumento de participação e discussão das comunidades rurais do município de Viçosa - Minas Gerais, através de seus conselheiros. No entanto, é preciso ressaltar algumas dificuldades percebidas no que tange à condução e manutenção do conselho, que, de forma análoga, é apresentado nos estudos de Duarte e Sayago (2006). Segundo os autores, os conselhos não têm cumprindo o seu papel de espaço de reflexão entre agricultores e técnicos sobre os reais problemas e potencialidades das políticas públicas, tomando como exemplo o PRONAF, tema sobre o qual, nas reuniões do CMDRS de Viçosa foram discutidas apenas as maneiras dos usos e destinação dos recursos, deixando de lado a possibilidade de um aprofundamento de discussão da eficácia de tal política. Além disso, os conselhos não apresentam um plano de formação e capacitação técnica dos seus conselheiros, técnicos e dos agricultores.

Somente no ano 2012, o CMDRS de Viçosa, com oito anos de funcionamento, começou o processo de capacitação dos seus conselheiros, como podemos observar na seguinte fala:

O professor R. iniciou suas palavras falando sobre a importância dos Conselhos do Desenvolvimento Sustentável, dos momentos de reflexão que geram a representação. Foi 
proposto uma capacitação de 10 a 15 minutos de capacitação, digo, em todas as reuniões do CMDRS/Viçosa [...] (CONSELHO MUNICIPAL DE DESENVOLVIMENTO RURAL SUSTENTÁVEL, 2012, Livro 1, p.44).

Ao mesmo tempo, esses conselhos têm uma visão tradicional sobre a promoção do desenvolvimento, com ações que se reduzem aos limites administrativos dos municípios e da agricultura, o que contraria a perspectiva de desenvolvimento territorial sustentável, que vem sendo cada vez mais fortalecida no âmbito das políticas públicas brasileiras.

Tendo em vista que os conselhos constituem um espaço de discussão de políticas públicas e desenvolvimento rural, a análise da variável participação se torna importante. Percebe-se na figura abaixo (Figura 1), que o número médio de participantes por reunião aumentou gradualmente, entretanto, esse aumento pode não ter relação direta com a participação dos agricultores familiares - atores sociais, foco do estudo - beneficiados pelas políticas públicas discutidas no âmbito do conselho, pois, o aumento de participantes se deu, sobretudo, pelo aumento da presença de técnicos nas reuniões. Esse fato deve-se, possivelmente, à organização do conselho, pois o mesmo prevê a participação apenas de um agricultor por comunidade. Assim, fica a seguinte indagação: até que ponto as discussões e decisões são repassadas a toda comunidade pelo conselheiro representante? 
EVOLUÇÃO, ACESSO E EFETIVIDADE DAS POLÍTICAS PÚBLICAS PARA A AGRICULTURA FAMILIAR NO GOVERNO LULA: UM ESTUDO DO CONSELHO MUNICIPAL DE DESENVOLVIMENTO RURAL SUSTENTÁVEL DE VIÇOSA, MINAS

Figura 1 - Número médio de participantes por reunião.

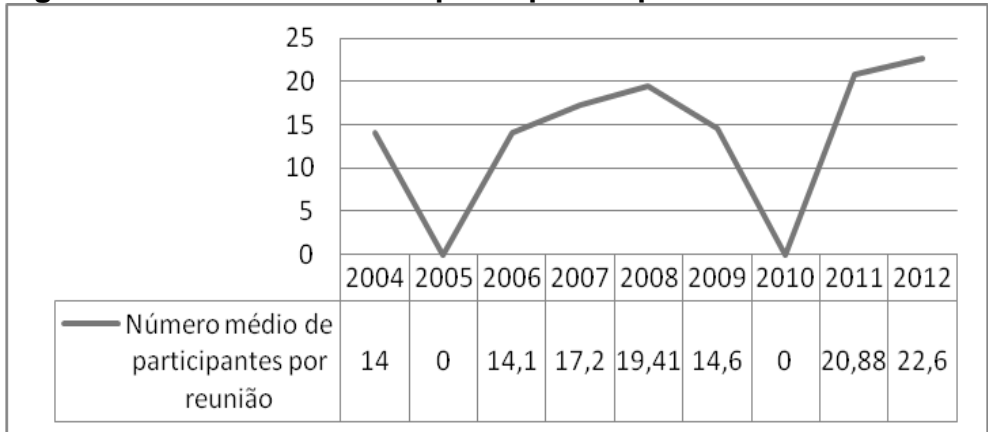

Fonte: Pesquisa documental realizada pelos autores, 2012.

Outra variável analisada se refere à frequência de reuniões por ano. Inicialmente, elas aconteciam bimestralmente, contudo, devido a uma necessidade sentida pelo conselho, decidiu-se por se fazê-la mensalmente. De acordo com um técnico da EMATER - MG, "[...] o grupo definiu pelas reuniões mensais, devido à importância das discussões e necessidades de decisão, também pelo fato de se as reuniões forem bimensais, os conselheiros se distanciam e podem até esquecer a data combinada" (Ata da reunião do CMDRS do dia 13 de março de 2007, p.17). Pode-se considerar essa mudança na frequência como algo positivo, pois partiu de todos os conselheiros a demonstração da necessidade referida. Por outro lado, houve a desativação do conselho por dois anos - 2005 e 2010. Além disso, em alguns anos não ocorreram todas as reuniões mensais como acordado previamente, como pode ser visto na figura abaixo (figura 2). 
Figura 2- Número de reuniões realizadas por ano.

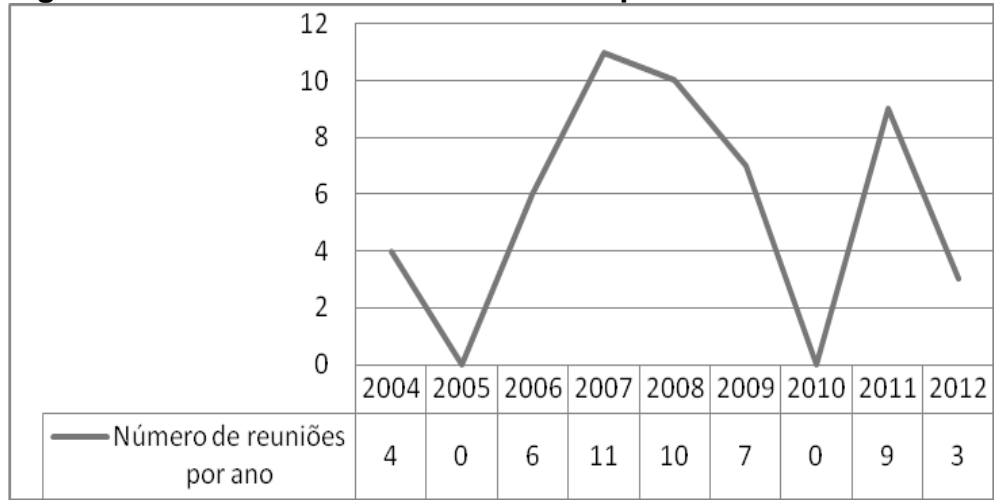

Fonte: Pesquisa documental realizada pelos autores, 2012.

Tendo em vista que este estudo aborda as políticas públicas criadas após a entrada do governo Lula no poder, priorizou-se a abordagem de questões como quais as principais políticas que foram discutidas no CMDRS de Viçosa. Percebe-se que a política pública que se destacou nas discussões do conselho foi o Programa Minas sem Fome, que é parte integrante do Programa Fome Zero, e em seguida o PRONAF' ${ }^{7}$. Em ambas as discussões foi possível perceber que o CMDRS não cumpriu uma de suas competências expostas no Regimento Interno, que seria o de "[...] promover a articulação e adequação de políticas públicas estaduais e federais buscando compatibiliza-las à realidade do município, e acompanhar, fiscalizar e avaliar sua implementação [...]" (Regimento interno do CMDRS de Viçosa, 2004), pois, as discussões se deram apenas no nível técnico e não no intuito de uma reflexão sobre a política em si. Por exemplo, nas discussões do Programa Minas sem Fome, o que se discutia era qual o tipo de semente mais demandada pelos agricultores, cabendo aos agricultores conselheiros votarem no tipo de semente e repassálas para suas comunidades. Em nenhum momento foi registrado em ata uma explicação do que seria esse programa.

${ }^{7}$ Ressalta-se que esta política não foi criada no governo Lula, apesar de ter ganhado força a partir deste. 
EVOLUÇÃO, ACESSO E EFETIVIDADE DAS POLÍTICAS PÚBLICAS PARA A AGRICULTURA FAMILIAR NO GOVERNO LULA: UM ESTUDO DO CONSELHO MUNICIPAL DE DESENVOLVIMENTO RURAL SUSTENTÁVEL DE VIÇOSA, MINAS GERAIS

O mesmo aconteceu nas discussões sobre o PRONAF, onde foi dado somente orientação sobre a destinação de verbas, sobre as dificuldades de seu acesso, quais linhas de crédito rural estavam ativas e que possuíam recursos disponíveis - PRONAF mulher, jovem, floresta -, não sendo feita uma explicação e nem mesmo uma reflexão sobre essa política pública. Embora as discussões sejam feitas principalmente no âmbito técnico, não se pode deixar de reconhecer que, ao fazer parte do CMDRS, os agricultores aproximam-se dessas políticas públicas, ou ao menos passam a ter conhecimento de sua existência. Com isso, ficam as seguintes dúvidas: será que os agricultores que fazem parte do conselho estão repassando para comunidades as quais representam o que ouvem $\mathrm{e}$ discutem durante as reuniões? $\mathrm{E}$, será que os agricultores que não fazem parte do conselho têm o mesmo nível ou um nível superior de entendimentos sobre essas políticas?

Em terceiro lugar na pauta de discussões está o Programa Luz para Todos, que não se diferenciou das demais discussões, ficando apenas no âmbito técnico. Todavia, foi possível prceber que o conselho funcionou como intervenção entre a empresa privada fornecedora do serviço e as comunidades, como pode ser percebido nas seguintes falas:

Será solicitado a CEMIG a apresentação da relação dos nomes dos beneficiários e o cronograma das ações [...] A CEMIG havia programado um atendimento na primeira etapa de 170.000 e este número foi para 280.000 atendimentos, conforme critérios estabelecidos pelo programa. No município de Viçosa, na primeira etapa foram beneficiadas 210 famílias. Para a segunda etapa, foram cadastrados 294 beneficiários (CONSELHO MUNICIPAL DESENVOLVIMENTO DE SUSTENTÁVEL. 2006, Livro 1, p.11).

Em quarto lugar nas discussões do conselho ficou o Programa Minha Casa Minha Vida Rural. Embora tenha sido discutido apenas em uma reunião, esse programa se diferenciou dos 
demais, pois não ficou apenas no âmbito técnico, e sim houve uma apresentação sobre o mesmo, explanado pela senhora M. B. B., representante do secretário municipal de ação social.

Outras políticas públicas e programas foram discutidos, entretanto, como não fazem parte do foco deste estudo, apenas serão citadas, quais sejam: Programa de Mecanização Agrícola, Bolsa Família, Programa Saúde da Mulher, Programa Nacional de Crédito Fundiário, Programa de Alfabetização de Jovens e Adultos e Bolsa Trabalho.

Além das orientações sobre diversas políticas públicas, notouse que as discussões no âmbito do conselho referem-se também às necessidades básicas do município de Viçosa, como podemos perceber em diversas falas nas quais existem uma acentuada preocupação com as estradas.

O senhor R. V. F. falou sobre os problemas nas estradas rurais, as dificuldades no transporte de insumos e produtos, o que foi apoiado por todos os outros conselheiros presentes. Ficou definido que por unanimidade que o CMDRS faria uma carta convite ao prefeito, ao secretário de obras e ao presidente da câmara, para que participem da próxima reunião no intuito de sensibilizálos sobre a precariedade das estradas rurais (CONSELHO MUNICIPAL DE DESENVOLVIMENTO RURAL SUSTENTÁVEL. 2007, Livro 1, p.14).

Por fim, é válido ressaltar as discussões sobre o problema das estradas, pois não é possível pensar em políticas públicas, como as citadas neste estudo se antes algumas necessidades básicas de infraestrutura - que obviamente também dependem de políticas públicas - para o meio rural, não estiverem sanadas.

\section{CONSIDERAÇÕES FINAIS}

Dentre os pontos fortes e fracos, é evidente que o CMDRS de Viçosa - Minas Gerais se constitui como um espaço de discussão 
EVOLUÇÃO, ACESSO E EFETIVIDADE DAS POLÍTICAS PÚBLICAS PARA A AGRICULTURA FAMILIAR NO GOVERNO LULA: UM ESTUDO DO CONSELHO MUNICIPAL DE DESENVOLVIMENTO RURAL SUSTENTÁVEL DE VIÇOSA, MINAS GERAIS

(mesmo que de forma tecnicista e pouco reflexiva) de algumas políticas públicas para o meio rural, e que talvez, sem este espaço essas discussões, em menor ou maior frequência, não seriam possíveis. Contudo, não é possível averiguar se as discussões empreendidas no referido espaço chegam até os demais agricultores nas comunidades, já que é eleito apenas um conselheiro para a representação de uma maioria. Outrossim, não é possível afirmar se as demandas dos agricultores chegam até o CMDRS, pois seria necessário a constatação de outro espaço de discussão coletiva dentro das comunidades. Desse modo, as considerações sobre o CMDRS são pertinentes e necessárias, já que uma das premissas apontadas durante o governo Lula incentiva uma maior aproximação entre os agricultores familiares e o Estado, no que se refere à criação e aplicabilidade das políticas públicas.

No que tange às políticas públicas discutidas no conselho identificou-se o Programa Minas sem Fome, o PRONAF (em três categorias), Programa Luz para Todos e o Programa Minha Casa Minha Vida Rural, como parte das políticas que atendem prioritariamente os agricultores familiares após a entrada do presidente Lula no Governo. Assim, o acesso dos agricultores familiares a estas políticas fica evidenciado. Porém, sua efetividade fica em dúvida, pois não foi possível identificar uma discussão aprofundada sobre as mesmas, e, igualmente, o reflexo positivo que estas têm causado no meio rural. Ademais, curiosamente, duas políticas públicas voltadas para agricultura familiar entendidas como "carro" chefe no Governo Lula não foram detectadas: o PAA e o PNAE. O que se pode inferir é que os agricultores dessa região não atendem aos editais ou possuem alguma dificuldade de produção e/ou comercialização, apesar de receberem assistência técnica do Estado através da EMATER.

De modo geral verifica-se uma evolução das políticas públicas durante o governo citado, pois antes as políticas eram voltadas majoritariamente para o agronegócio. $\mathrm{O}$ que se notou no caso estudado foi uma falta de articulação entre os agricultores familiares, o órgão de assistência técnica (EMATER), o Estado, pesquisadores, ONGs, dentre outros, para que possam acessar outras políticas e melhorar a eficácia daquelas que já estejam 
acessando. Nesse sentido, percebe-se que os conselhos têm papel fundamental nessa articulação, funcionando como um mediador entre tais atores. Além disso, o CMDRS se constitui em um espaço de capacitação (mesmo que em pequena proporção) e informação para os agricultores, com possibilidades de formar laços de confiança, de maneira que propicie que estes trabalhem de forma coletiva para obterem vantagem ao acesso das políticas públicas e, concomitantemente, poderem ter acesso a um mercado cada vez mais competitivo.

Por fim, cumpre ressaltar que este trabalho não tem por intento dizer sobre uma realidade maior, ou seja, diz respeito apenas à "realidade" rural de Viçosa nos limites atendidos pelo CMDRS, contribuindo dessa maneira com algumas reflexões que tem sido feitas acerca da temática. Quando se refere à "realidade", os desafios se tornam ainda maiores, pois esta é muito mais complexa do que uma pesquisa possa delimitar. Dessa maneira, acredita-se que outros trabalhos devem ser realizados para que se possa demarcar com maior precisão os limites e as potencialidades do acesso às políticas públicas por parte dos agricultores familiares e que possam responder os demais questionamentos surgidos durante este trabalho.

\section{REFERÊNCIAS BIBLIOGRÁFICAS}

ABRAMOVAY, R. Agricultura, Diferenciação Social e Desempenho Econômico. Projeto IPEA-NEAD/MDA - Banco Mundial, São Paulo: FEA-USP, 2000.

ALENTEJANO, P. R. R. A política de assentamentos rurais do governo $\mathrm{FHC}$ e os Desafios da reforma agrária no Brasil do século XXI. São Paulo. Agrária, n. 1, p. 2-15, 2004

AVRITZER, L.; PEREIRA, M.L. D. Democracia, participação e instituições híbridas. Revista Teoria \& Sociedade, Instituições híbridas e participação no Brasil e na França, n. especial, mar. 2005. Disponível em: 
EVOLUÇÃO, ACESSO E EFETIVIDADE DAS POLÍTICAS PÚBLICAS PARA A AGRICULTURA FAMILIAR NO GOVERNO LULA: UM ESTUDO DO CONSELHO MUNICIPAL DE DESENVOLVIMENTO RURAL SUSTENTÁVEL DE VIÇOSA, MINAS

http://www.democraciaparticipativa.org/pg_instituicoes_hibridas.html >. Acesso em 18 de abril de 2012.

BITTENCOURT, G. A.; BIANCHINI, V. Agricultura familiar na região sul do Brasil, Consultoria UTF/036-FAO/INCRA, 1996.

BULLA, L. C.; LEAL, M. L. M. A participação da sociedade civil no Conselho Municipal de Assistência Social: o desafio de uma representação democrática. Textos \& Contextos, v. 3, n. 1, p. 1-13, 2004.

CARMO, M. S.. Agroecologia: novos caminhos para a agricultura familiar. Revista Tecnologia \& Inovação agropecuária. Dez de 2008.

CERQUEIRA, P. S.; ROCHA, A. G. P.; COELHO, V. P. Agricultura familiar e políticas públicas: algumas reflexões sobre o Programa de Aquisição de Alimentos no estado da Bahia. In: II Encontro de Economia Baiana, Bahia, 2006.

COELHO, V. S. R. P. Conselhos de saúde enquanto instituições políticas: o que está faltando? In: COELHO, Vera Schattan R. P.; NOBRE, Marcos (Org.). Participação e deliberação: teoria democrática e experiências institucionais no Brasil contemporâneo. São Paulo: 34Letras, v. 1, p. 255-269, 2004.

CONSELHO DE DESENVOLVIMENTO RURAL SUATENTÁVEL. Viçosa. Regimento Interno,2004, p.3

CONSELHO MUNICIPAL DE DESENVOLVIMENTO RURAL SUSTENTÁVEL. Viçosa. Ata da reunião realizada no dia 12 de dezembro 2006. 2006, Livro 1, p.11.

CONSELHO MUNICIPAL DE DESENVOLVIMENTO RURAL SUSTENTÁVEL. Viçosa. Ata da reunião realizada no dia $\mathbf{9}$ de janeiro de 2007. Livro 1, p.14. 
CONSELHO MUNICIPAL DE DESENVOLVIMENTO RURAL SUSTENTÁVEL. Viçosa. Ata da reunião realizada no dia 5 de dezembro, 2012. Livro 1, p.44

CÔRTES, S. M. V. Fóruns participativos e governança: uma sistematização das contribuições da literatura. In: LUBAMBO, Catia; COELHO, Denilson Bandeira; MELO, Marcus André (Org.). Desenho institucional e participação política: experiência no Brasil contemporâneo. Petrópolis: Vozes, v. 1, p. 13-32, 2005.

DENARDI, R. A. Agricultura familiar e políticas públicas: alguns dilemas e desafios para o desenvolvimento rural sustentável. In: Agroecologia e Desenvolvimento Rural Sustentável. Porto Alegre, v.2, n.3, jul./set., 2001.

DUARTE, L. M. G. e SAYAGO, D. Dinâmicas Associativas da Agricultura Familiar e Funcionamento dos Conselhos Municipais de Desenvolvimento Rural Sustentável. In: Associativismo, Cooperativismo e Economia Solidária no Meio Rural. Brasília. Universidade de Brasília, Centro de Estudos Avançados Multidisciplinares - CEAM. Núcleo de Estudos Agrários - NEAGRI. v.6.n.24, pp. 205-220. 2006.

GASSON, R.; ERRINGTON, A. The farm family business. Waliinglord, Cab International.

GAZOLLA, M.; SCHNEIDER, S. As duas "caras" do Pronaf: Produtivismo ou fortalecimento da produção para autoconsumo? In: XLIII Congresso da Sociedade Brasileira de Economia e Sociologia Rural, Ribeirão Preto - SP. Anais..., CD Rom 2005.

GIL, A. C. Como elaborar projetos de pesquisa. 4. Ed. São Paulo: Atlas, 2002.

GOHN, M.G. Conselho gestores e participação sociopolítica. São Paulo, 2001. 
EVOLUÇÃO, ACESSO E EFETIVIDADE DAS POLÍTICAS PÚBLICAS PARA A AGRICULTURA FAMILIAR NO GOVERNO LULA: UM ESTUDO DO CONSELHO MUNICIPAL DE DESENVOLVIMENTO RURAL SUSTENTÁVEL DE VIÇOSA, MINAS

GRISA, C. et al. Programa de Aquisição De Alimentos (PAA) em perspectiva: Apontamentos e questões para o debate. In: Seminário Temático Programa de Aquisição de Alimentos (PAA) 2009.

GUANZIROLI, C.; CARDIM, S. E. (Coord.). Novo Retrato da Agricultura Familiar: $O$ Brasil redescoberto. Brasília: Projeto de Cooperação Técnica FAO/INCRA, fev/2000. 74 p. Disponível em <http://www.incra.gov.br/fao/pub3.html>. Acesso 28/03/2012.

HESPANHOL, R. A.M.. Mudança de concepção das políticas públicas para o campo brasileiro: o Programa de Aquisição de Alimentos (PAA). Revista Electrónica de Geografía y Ciencias Sociales, agosto 2008. Disponível em <http://www.ub.edu/geocrit/sn/sn-270/sn-270-79.htm>. Acesso em 5 de abril de 2012.

LOUREIRO, K. Neoliberalismo e Questão agrária: as consequências para o campo brasileiro. In: ANAIS ELETRÔNICOS DO IV ENCONTRO DA ANPUH-ES. História, representações e narrativas, Vitória, 2003.

MOREIRA, R. J.. Críticas ambientalistas à Revolução Verde. In: X World Congress of Rural Sociology - IRSA; XXXVII Brazilian Congress of Rural Economic and Sociology - Sober. Rio de Janeiro. n. 38, 2000.

OLIVEIRA, E. et al. Análise de conteúdo e pesquisa na área da educação. Revista Diálogo Educacional, v. 4, n. 9, p. 1-17, maio/agosto de 2003.

PEDRON, F. A.; KLEIN, A.a L.. Políticas públicas para a atividade de turismo rural. Estudo da utilização dos recursos do PRONAF. Revista Extensão Rural, Santa Maria, dezembro 2004. Disponível em < http://w3.ufsm.br/extensaorural/art4ed11.pdf>. Acesso em 4 de abril de 2012. 
SABOURIN, E. 2007, Que política pública para a agricultura familiar no segundo governo Lula? Sociedade e Estado, v.22, n.3, p.715751, Brasília, 2007,

SANTOS, L. C. R.. Reflexão sobre o Programa Nacional de Alimentação Escolar - PNAE e a Agricultura Familiar no Nordeste. Brasília. 2009.

SÁ-SILVA, J. R.; ALMEIDA, C. D.; GUINDANI, J. F. Pesquisa documental: pistas teóricas e metodológicas. In: Revista Brasileira de História \& Ciências Sociais, n. 1, Julho de 2009.

SAYAGO, D. Os Conselhos de Desenvolvimento Territorial: entre a participação e a representação. Revista Brasileira de Gestão e Desenvolvimento Regional, G\&DR. Taubaté, SP, Brasil, v. 3, n. 4 (número especial), p. 9-21, nov/2007.

TATAGIBA, L. Os conselhos gestores e a democratização das políticas públicas no Brasil. In: DAGNINO, Evelina (Org.). Sociedade civil e espaços públicos no Brasil. São Paulo: Paz e Terra, p. 47103, 2002,

TEIXEIRA, E. C. 0 Papel das Políticas Públicas no Desenvolvimento Local e na Transformação da Realidade. Bahia: AATR, 2002.

TRIVIÑOS, A. N. S. Introdução à pesquisa em ciências sociais - a pesquisa qualitativa em educação. São Paulo: Atlas, 1987. 